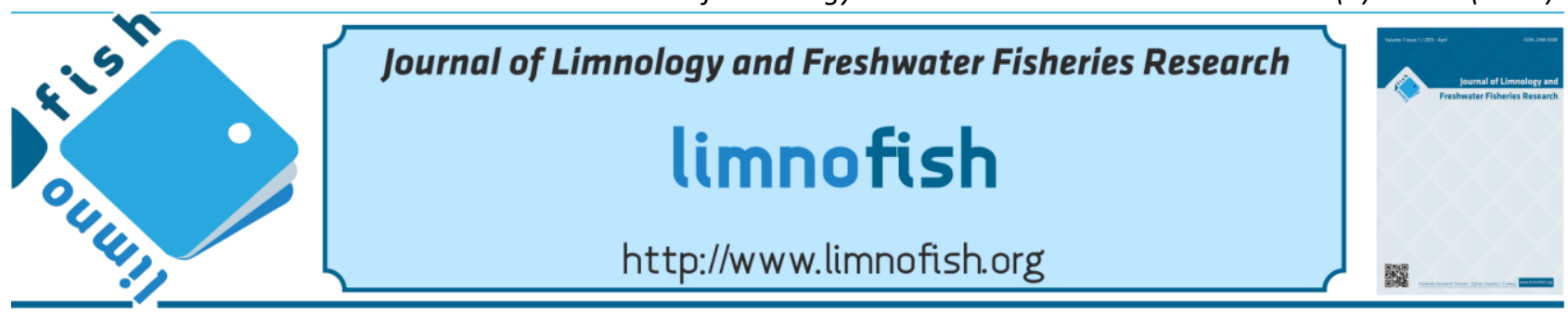

\title{
Chlorella vulgaris Beyerinck [Beijerinck] (Chlorophyta) Suşlarının Kesikli Kültür Sisteminde Yığın Kültürrlerinin Üretimi Üzerine Bir Çalışma
}

\author{
Dilek YALÇIN DUYGU* iD \\ Gazi Üniversitesi Gazi Eğitim Fakültesi, Orta Öğretim Fen ve Matematik Alanları, Ankara, Türkiye
}

\section{$\ddot{O} Z$}

Bu çalışmada, tatlısu birikintilerinde yaygın olarak bulunan, tek hücreli bir yeşil alg olan Chlorella vulgaris türünün izolasyonu, kültür koşullarının oluşturulması ve yığın kültürlerinin elde edilmesi amaçlanmıştır. $C$. vulgaris gıda, kozmetik ve eczacılık sektöründe kullanıldığı gibi, son yıllarda biyodizel üretiminde ve atık suların arıtımında da umut verici hale gelmiştir. Tatlısu birikintilerinden izole edilen C. vulgaris suşları kesikli kültür sistemi oluşturularak, 100, 200, 500, 1000, 2000 ve 4000 ml'lik hacimlerde üretimleri yapılmıştır. Suşların başlangıç inokulum miktarı, uygun $\mathrm{pH}$, sıcaklık, havalandırma gibi etmenler denenerek optimum kültür koşulları oluşturulmuştur. 4000 ml'lik yığın kültürlerin 120 . saatte yapılan hücre sayımlarında en yüksek değer AUFFH suşunda $6,8 \times 10^{4} \mathrm{~h} / \mathrm{ml}$ olarak tespit edilmiș bu sușu sırasıyla; TOH $6,7 \times 10^{4} \mathrm{~h} / \mathrm{ml}$, UIK $6,3 \times 10^{4} \mathrm{~h} / \mathrm{ml}$,

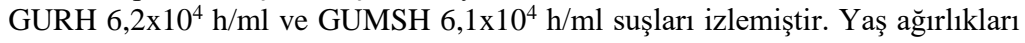
açısından 4000 ml'lik yığın kültürler için yine AUFFH $152(\mathrm{~g} / 2000 \mathrm{ml})$ ile en yüksek miktar elde edilirken onu sırasıly TOH 129,6 (g/2000 ml), GURH 120,8 (g/2000 ml), GUMSH 84,3 (g/2000 ml), UIK 48,8 (g/2000 ml) takip etmiştir.

\section{MAKALE BILGISI}

ARAŞTIRMA MAKALESI
$\begin{array}{ll}\text { Geliş } & : 23.12 .2016 \\ \text { Düzeltme } & : 30.03 .2017 \\ \text { Kabul } & : 07.04 .2017 \\ \text { Yayım } & : 21.08 .2017\end{array}$

DOI: $10.17216 /$ LimnoFish.280547

\section{* SORUMLU YAZAR}

dilekduygu06@hotmail.com

Tel : +90532328 2147

Anahtar kelimeler: Chlorella vulgaris, mikroalg, yığın kültür, kesikli kültür sistemi

A Study on the Production of Batch Cultures in Semi-Continuous Culture System of Chlorella vulgaris Beyerinck [Beijerinck] (Chlorophyta) Strains

\begin{abstract}
In this study, it is aimed to isolate Chlorella vulgaris strain, a single-celled green algae that is common in freshwater deposits, to establish culture conditions and to obtain batch cultures. $C$. vulgaris has been used in food, cosmetics and pharmaceutical industries as well as become encouraging for the production of biodiesel and the treatment of wastewater in recent years. $C$. vulgaris strains isolated from freshwater deposits were cultivated in a semi-continuous culture system of 100, 200, 500, 1000, 2000 and 4000 $\mathrm{ml}$. Subsequently growth factors such as initial inoculum amount of the strains, appropriate $\mathrm{pH}$, temperature and ventilation were tested in order to optimize the conditions. The highest value in the cell counts of $4000 \mathrm{ml}$ batch cultures at the $120^{\text {th }}$ hours was determined as $6.8 \times 10^{4} \mathrm{~h} / \mathrm{ml}$ in AUFFH strain respectively the others were as follows: TOH $6.7 \times 10^{4} \mathrm{~h} / \mathrm{ml}$, UIK $6.3 \times 10^{4} \mathrm{~h} / \mathrm{ml}$, GURH $6.2 \times 10^{4} \mathrm{~h} / \mathrm{ml}$ and GUMSH $6.1 \times 10^{4} \mathrm{~h} / \mathrm{ml}$. The highest amount in terms wet weight for $4000 \mathrm{ml}$ batch cultures was obtained as AUFFH $152(\mathrm{~g} / 2000 \mathrm{ml})$, this value was followed by TOH $129.6(\mathrm{~g} / 2000 \mathrm{ml})$, GURH $120.8(\mathrm{~g} / 2000 \mathrm{ml})$, GUMSH 84.3 (g/2000 ml), UIK 48.8 (g/2000 ml).
\end{abstract}

Keywords: Chlorella vulgaris, microalgae, batch culture, semi-continuous system

\section{Alıntılama}

Yalçın Duygu D. 2017. Chlorella vulgaris Beyerinck [Beijerinck] (Chlorophyta) Suşlarının Kesikli Kültür Sisteminde Yığın Kültürlerinin Üretimi Üzerine Bir Çalışma. LimnoFish. 3(2): 61-67. doi: 10.17216/LimnoFish.280547

\section{Giriş}

Mikroalgler, karbondioksiti güneş enerjisi yardımı ile biyokimyasal maddelere dönüştürebilme yeteneğine sahip olan fotosentetik mikroorganizmalardır. Bunu da karasal bitkilerden 10 kat fazla verimle yerine getirmektedirler (Murdock ve Wetzel 2009; Brennan ve Owende 2009). 50.000'den fazla mikroalg türü bulunmakla birlikte, bunların yaklașık 30.000'i üzerinde çalıș1lıp analiz edildiği tahmin edilmektedir (Richmond 2004). Mikroalg kültürleri sadece yetiştiricilikle uğraşanların değil, aynı zamanda bitki fizyologları ve biyomühendislerin uzun yillar boyunca özel ilgi duydukları ve çalıştıkları bir konu olmuştur. Fotosentezi çalışmak amacıyla tek hücreli yeşil alglerden Chlorella'nın deneylerde kullanılmasından 
sonra, bazı mikroalglerin de gün içinde biyokütlelerini defalarca artırabildikleri ve kat1 maddelerinin $\% 50$ 'den fazla proteinden oluştuğu bulunmuştur. Almanya'da 1940'ların başında mikroalglerin büyük miktarlarda üretilmesi için araştırmalar yapılmış, takip eden yıllarda çeşitli ülkelerde alglerin büyük ölçekli üretiminde verim, kimyasal kompozisyon ve azot fiksasyonu konularında çalışılmıştır (Cirik ve Gökpınar 1993). Son yıllarda, Asya'da geniş ölçekli mikroalg özellikle Chlorella sp. fabrikalarda üretilmekte, genellikle sağlık gıdası olarak kültürleri yapılmaktadir. Ototrofik, miksotrofik ve heterotrofik metotlar ile bunların kombinasyonlarıyla üretim sistemleri kurulmuş olup, üretim maliyetleri bakımından her bir sistemin avantaj ve dezavantajları değerlendirilmektedir (Iwamoto 2004; Vaiciulyte vd. 2014). Halen araştırmacılar, başta biyodizel üretimi olmak üzere gıda, kozmetik, su ürünleri yetiştiriciliği, eczacılık, atık su arıtımı, anti-tümör ve anti-bakteriyel bileşikler gibi ekonomik değerleri yüksek içeriklerinden dolayı mikroalg türleri üzerinde çalışmalarına devam etmektedirler (Borowitzka ve Borowitzka 1988; Cohen 1999; Rasmussen vd. 2007; Hosikian vd. 2010).

Chlorella; proteince zengin olmas1 (kuru ağırlığının yaklaşık \%70'i), çeşitli vitaminler $\left(\mathrm{B}_{12}\right.$, $\mathrm{B}_{1}, \mathrm{~B}_{2}$, pantotenik asit, niasin, tokoferon) içermesi açısından insan gıdası ve hayvan yemi olarak kullanılması, ürettiği pigment maddelerinin (karotenler, ksantofiller) hayvan dokularına, kümes hayvanlarının yumurtalarına sarı renk kazandırması, çeşitli antibiyotikler (korellin) içermesi ve oksidasyon kapasitelerinin yüksek olması açısından önem taşıyan bir mikroalg türüdür (Santhosh vd. 2016). Son y1llarda, immobilize C. vulgaris'in ağır metal emilimi üzerinde yapılan çalışmalar başarılı sonuçlar vermiş olup, atık suların temizlenmesinde kullanılmaya başlanmışlardır (Chu vd. 2009; Ruiz-Marin vd. 2010). C. vulgaris en hizlı üreyen yeşil mikroalg olarak bilinmektedir. Çeşitli besi ortamları ve farklı kültür koşullarında, içeriğindeki yağ miktarı artırılarak biyodizel üretimi konusundaki çalışmalar halen devam etmektedir (Vaiciulyte vd. 2014; Al-lwayzy vd. 2014; Aguoru ve Okibe 2015; Hamedi vd. 2016). Mikroalg yetiştiriciliğinde, farklı besi ortamları ve kültür tekniklerinin kullanılması ile ilgili araştırmaların çoğalması hem bilim dünyası hem de çeşitli sanayi dalları için önem taşımaktadır. $\mathrm{Bu}$ nedenle, çalışmamız $C$. vulgaris suşlarının izole edilmesi, uygun kültür koşullarının oluşturularak laboratuvar şartlarında üretilip yığın kültürlerinin yetiştirilmesi ve bu değerli doğal kaynağın ülkemiz sanayisine kazandırılması için bir ön çalışma olarak amaçlanmış ve yürütülmüştür.

\section{Materyal ve Metot \\ İzolasyon}

Çalışmamızda kullandığımız C. vulgaris suşları Ankara'daki farklı havuzlardan ve su birikintilerinden toplanan örneklerden izole edilmiştir. Suşların izolasyonunda tek koloniden üretme temeline dayalı saf kültür elde etme yöntemi kullanılmıştır (Parvin vd. 2007; CSIRO 2016). Toplanan örnekler laboratuvar ortamında ön zenginleştirme için sıvı besiyerine $\left(\mathrm{MgSO}_{4} .7 \mathrm{H}_{2} \mathrm{O}\right.$ $2,50 \mathrm{~g}, \mathrm{KNO}_{3}-5,0 \mathrm{~g}, \mathrm{KH}_{2} \mathrm{PO}_{4}-1,25 \mathrm{~g}, \mathrm{FeSO}_{4} .7 \mathrm{H}_{2} \mathrm{O}-$ 0,009 g, Distile Su-1000 ml) alınmıştır. Birkaç gün sonra lam üzerine örnekler alınıp mikroskopta $C$. vulgaris'in karakteristik sporları tür teşhis anahtarı kullanılarak tespit edilmiştir (Prescott, 1973). Daha sonra kültürler $\left(\mathrm{KNO}_{3}-2,5 \mathrm{~g}, \mathrm{MgSO}_{4} \cdot 7 \mathrm{H}_{2} \mathrm{O}-1,250 \mathrm{~g}\right.$, $\mathrm{KH}_{2} \mathrm{PO}_{4}-0,62 \mathrm{~g}, \mathrm{FeSO}_{4} .7 \mathrm{H}_{2} \mathrm{O}-0,009$ g, Agar-5 gr, Distile $\mathrm{Su}-500 \mathrm{ml}$ ) bileşiminden oluşan katı besi ortamlarına ekilmiştir. Agar plakları üzerinde üreyen C. vulgaris kolonileri tekrar ön zenginleştirme besi ortamına alınarak saf kültürleri elde edilmiştir.

\section{Kültür Koşulları}

Yığın kültürlerin süspansiyon halinde tutulması için bir akvaryum motoru ile kültürlere hava verilmiştir. Kültürlerin 1 şı ihtiyaçları yapay 1şıklandırma ile gerçekleştirilmiştir. Iş1k kaynağ 1 $\left(150 \mu \mathrm{mol} . \mathrm{m}^{-2} . \mathrm{s}^{-1}\right)$ kültürlerden $22 \mathrm{~cm}$ uzaklığa, yatay şekilde, arkadan verilmek suretiyle yerleştirilmiştir. Kültürlere 16:8 aydınlık/karanlık periyodu uygulanmış ve $22-25^{\circ} \mathrm{C}$ 'de oda sicaklığında yetiştirilmiştir.

\section{Yığın Kültürlerin Yetiştirilmesi}

Çalışmaların başlangıcında inokulum miktarının tespiti için 10 ml'lik besiyerlerine seri $\left(10^{-1}, 10^{-2}, 10^{-3}\right)$ ekimler yapılmıştır. Uygun kültür koşullarında inkübasyona bırakılan kültürlerden üreme olan ve olmayan tüpler kaydedilmiş ve $\left(10^{-1}\right)$ dilüsyon tüplerinde verimli üreme tespit edilmiştir. İnokulum miktarının tespit edilmesiyle $9 \mathrm{ml}$ besiyeri +1 ml süspanse kültür olacak şekilde ekimler gerçekleştirilmiştir. Yığın kültürlerin ekimlerine 100 $\mathrm{ml}$ ile başlanmış, ardından $200 \mathrm{ml}, 500 \mathrm{ml}, 1000 \mathrm{ml}$, $2000 \mathrm{ml}$ ve $4000 \mathrm{ml}$ olacak şekilde küçük hacimden büyük hacime doğru gidilmiştir. Yığın kültürlerin ürteminde Bold Wynne besi ortam1 $\left(\mathrm{NaNO}_{3}-0,250 \mathrm{~g}\right.$; $\mathrm{MgSO}_{4} .7 \mathrm{H}_{2} \mathrm{O}-0,075 \mathrm{~g} ; \mathrm{K}_{2} \mathrm{HPO}_{4}-0,075 \mathrm{~g} ; \mathrm{KH}_{2} \mathrm{PO}_{4-}$ $0,0175 \mathrm{~g} ; \mathrm{NaCl}-0,025 \mathrm{~g} ; \mathrm{CaCl}_{2} \cdot \mathrm{H}_{2} \mathrm{O}-0,025 \mathrm{~g}$; Distile Su-1000 ml) kullanılmıştır. C. vulgaris kültürlerinin kodlamaları ve alındıkları ortamlar; Gazi Üniversitesi Rektörlük Havuzu (GURH), Gazi Üniversitesi Mediko Sosyal Havuzu (GUMSH), Ankara Üniversitesi Fen Fakültesi Havuzu (AUFFH), Turizm Otelcilik Havuzu (TOH), Ulus İnşaat Kuyusu (UIK) şeklindedir. 


\section{Mikroalg Büyümesinin Ölçümü}

Hücre yoğunlukları, Thoma lamındaki 16 kareye düşen hücrelerin sayımıyla tespit edilmiştir. Hücre sayımları ekim işleminin başlangıcında (0), (24), (48), (96) ve (120) saatlerde yapılmıştır. Hücre yoğunlukları (Guillard ve Sieracki 2005)'e göre aşağıdaki formül ile hesaplanmıştır:

$$
H \text { ücre sayısl }=\frac{\left(\begin{array}{c}
16 \text { kareye düşen } \\
\text { toplam hücre sayısı }
\end{array}\right) \times 4000(1 \text { karenin hacmi })}{16}
$$

Verim saptamalarının tayin edilmesi kültürlerin ekiminin 7. gününde yaş ağırlıklarının ölçülmesiyle yapılmıştır. 100 ml'lik kültürlerden 50 ml, 200 ml'lik kültürlerden $100 \mathrm{ml}, 500 \mathrm{ml}$ 'lik kültürlerden $250 \mathrm{ml}$, 1000 ml'lik kültürlerden $500 \mathrm{ml}, 2000$ ml'lik kültürlerden 1000 ml, 4000 ml'lik kültürlerden 2000 $\mathrm{ml}$ alınarak santrifüj edilmiștir. Elde edilen süpernatant etüvde belli süre bekletilip fazla olan sıv1 kısmı uçurulmuş, hassas terazide ölçülerek yaş ağırlıkları tayin edilmiştir (Borçaklı 1987).

\section{Bulgular}

C.vulgaris suşlarının hücre sayıları ve biyomas sonuçları Tablo 1'de verilmiştir. Ekimi takip eden saatler boyunca hücre sayıları sürekli artarak devam etmiştir. Ortamdaki besiyeri hücreler tarafindan yaklaşık 20 günde tüketilmiş ve besiyeri seviyesi düşmüştür. Hücre sayıları ilk aşılama miktarına bağlı olarak artmış, biyomas ağırlıkları ise ekimi yapılan hacimlere göre, ortamda yetişme hızlarına ve ortama alışma sürelerine göre farkl1lık göstermiştir. En yüksek hücre yoğunluğu ve biyomas miktarı 4000 ml'lik hacim için AUFFH suşunda tespit edilmiştir. AUFFH suşunun hücre yoğunluğu $6,8 \times 10^{4} \mathrm{~h} / \mathrm{ml}$, biyomas miktar1 $152(\mathrm{~g} / 2000 \mathrm{ml})$ olarak bulunmuştur (Şekil 1 ve 2).

C. vulgaris suşlarının ekimi takiben 7 . günde 1 şık mikroskobunda yapılan incelemelerine ait fotoğraf çekimleri Şekil 3'de verilmiştir.

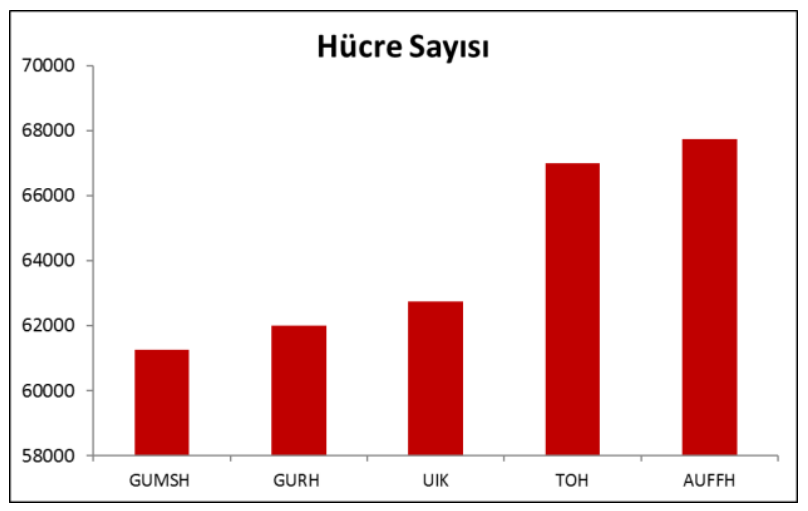

Şekil 1. $4000 \mathrm{ml}$ kültürlerin hücre sayımları

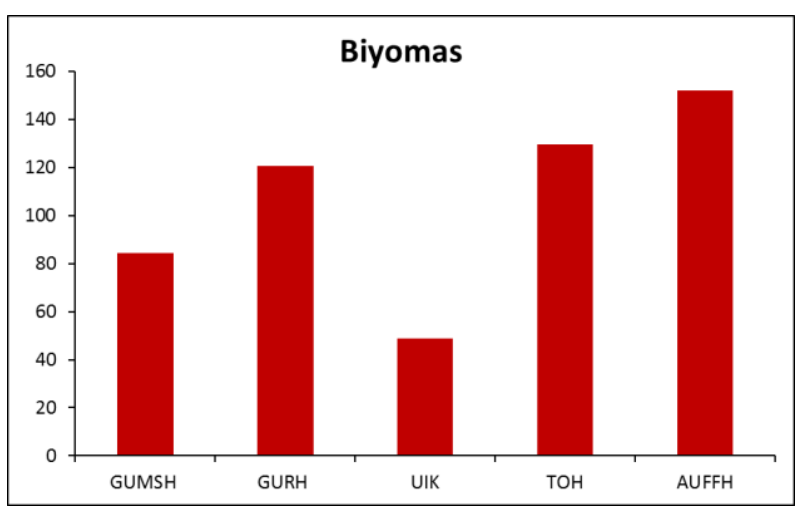

Şekil 2. $4000 \mathrm{ml}$ kültürlerin yaş ağırlıkları

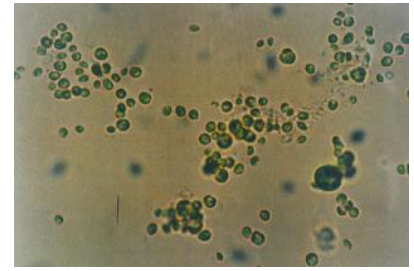

(a)

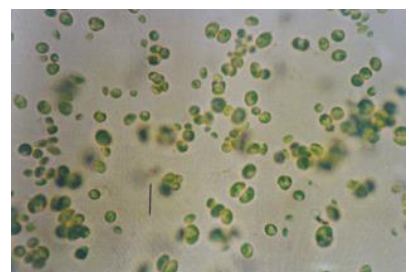

(c)

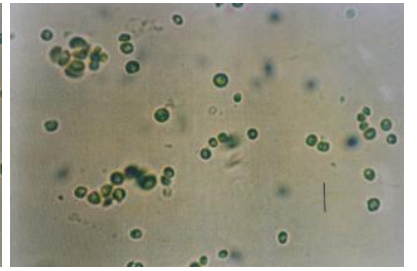

(b)

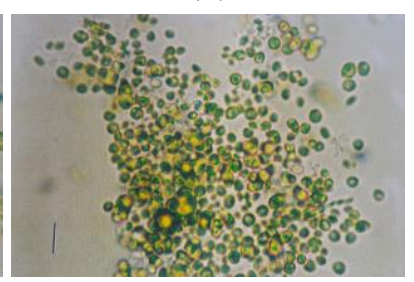

(d)

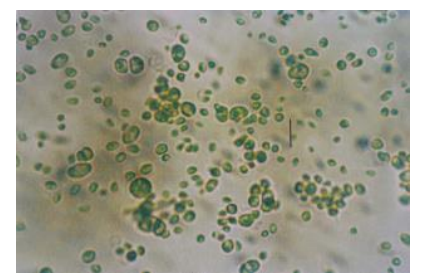

(e)

Şekil 3. Mikroskop Resimleri (10x40) (a) GURH; (b) GUMSH; (c) AUFFH; (d) TOH; (e) UIK

\section{Tartışma ve Sonuç}

C. vulgaris Chlorophyta divisio'suna mensup olup, 1890 'da Beyerinck tarafindan tek hücreli, 1-6 $\mu$ arasında değişen boyutlarda, elipsoid, küresel veya düz hücrelerden oluşan, normalde sadece tek kromatoforlu olarak tanımlanmıştır. Beyerinck tarafindan tanımlanmasından bu yana bu tanımlama çok az değişmiştir (Shihira 1965). Nitekim Prescott (1968, 1973) ve Baydar (1990)

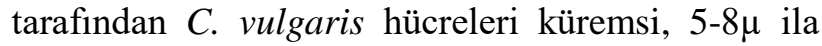
5-10 $\mu$ büyüklükte, kloroplast periental, fincal, bazen prenoidsiz, diğer algler arasında yayılmakta veya bazen yaklaşı1k saf yetişmiş olarak bulunmakta olup morfolojik olarak da kokkoid tipe girdiği ifade edilmiştir. 
Tablo 1. C.vulgaris Suşlarının Hacimlere Göre Hücre Sayıları ve Biyomas Ağırlıkları

\begin{tabular}{|c|c|c|c|c|c|c|c|}
\hline \multirow[b]{2}{*}{ Kültürler } & \multirow{2}{*}{$\begin{array}{l}\text { Hacim } \\
(\mathrm{ml})\end{array}$} & \multicolumn{5}{|c|}{ Saatlere Göre Hücre Miktarı (h/ml) } & \multirow{2}{*}{ Biyomas } \\
\hline & & 0 & 24 & 48 & 96 & 120 & \\
\hline \multirow{6}{*}{ GURH } & 100 & $3,6 \times 10^{4}$ & $4,2 \times 10^{4}$ & $4,8 \times 10^{4}$ & $5,5 \times 10^{4}$ & $5,8 \times 10^{4}$ & $1,3(\mathrm{~g} / 50 \mathrm{ml})$ \\
\hline & 200 & $3,9 \times 10^{4}$ & $4,6 \times 10^{4}$ & $4,8 \times 10^{4}$ & $5,6 \times 10^{4}$ & $5,9 \times 10^{4}$ & $3,5(\mathrm{~g} / 100 \mathrm{ml})$ \\
\hline & 500 & $3,4 \times 10^{4}$ & $3,8 \times 10^{4}$ & $4,5 \times 10^{4}$ & $5,1 \times 10^{4}$ & $5,4 \times 10^{4}$ & $3,5(\mathrm{~g} / 250 \mathrm{ml})$ \\
\hline & 1000 & $3,3 \times 10^{4}$ & $3,8 \times 10^{4}$ & $4,1 \times 10^{4}$ & $4,2 \times 10^{4}$ & $4,3 \times 10^{4}$ & $5,8(\mathrm{~g} / 500 \mathrm{ml})$ \\
\hline & 2000 & $2,3 \times 10^{4}$ & $3,1 \times 10^{4}$ & $4,1 \times 10^{4}$ & $4,4 \times 10^{4}$ & $4,8 \times 10^{4}$ & $12,6(\mathrm{~g} / 1000 \mathrm{ml})$ \\
\hline & 4000 & $2,9 \times 10^{4}$ & $3,9 \times 10^{4}$ & $5,9 \times 10^{4}$ & $5,7 \times 10^{4}$ & $6,2 \times 10^{4}$ & $120,8(\mathrm{~g} / 2000 \mathrm{ml})$ \\
\hline \multirow{6}{*}{ GUMSH } & 100 & $3,9 \times 10^{4}$ & $4,6 \times 10^{4}$ & $5,1 \times 10^{4}$ & $5,7 \times 10^{4}$ & $6,9 \times 10^{4}$ & $1,9(\mathrm{~g} / 50 \mathrm{ml})$ \\
\hline & 200 & $3,5 \times 10^{4}$ & $3,7 \times 10^{4}$ & $4,1 \times 10^{4}$ & $4,2 \times 10^{4}$ & $4,8 \times 10^{4}$ & $2,8(\mathrm{~g} / 100 \mathrm{ml})$ \\
\hline & 500 & $3,3 \times 10^{4}$ & $4,6 \times 10^{4}$ & $5,1 \times 10^{4}$ & $5,7 \times 10^{4}$ & $6,1 \times 10^{4}$ & $5,7(\mathrm{~g} / 250 \mathrm{ml})$ \\
\hline & 1000 & $2,8 \times 10^{4}$ & $2,9 \times 10^{4}$ & $3,5 \times 10^{4}$ & $3,6 \times 10^{4}$ & $4,1 \times 10^{4}$ & $8,3(\mathrm{~g} / 500 \mathrm{ml})$ \\
\hline & 2000 & $2,2 \times 10^{4}$ & $2,7 \times 10^{4}$ & $4,2 \times 10^{4}$ & $4,4 \times 10^{4}$ & $4,7 \times 10^{4}$ & $19,0(\mathrm{~g} / 1000 \mathrm{ml})$ \\
\hline & 4000 & $3,2 \times 10^{4}$ & $3,9 \times 10^{4}$ & $4,7 \times 10^{4}$ & $6,1 \times 10^{4}$ & $6,1 \times 10^{4}$ & $84,3(\mathrm{~g} / 2000 \mathrm{ml})$ \\
\hline \multirow{6}{*}{ AUFFH } & 100 & $4,3 \times 10^{4}$ & $4,6 \times 10^{4}$ & $5,1 \times 10^{4}$ & $5,3 \times 10^{4}$ & $6,5 \times 10^{4}$ & $1,1(\mathrm{~g} / 50 \mathrm{ml})$ \\
\hline & 200 & $4,1 \times 10^{4}$ & $4,7 \times 10^{4}$ & $4,9 \times 10^{4}$ & $5,7 \times 10^{4}$ & $6,2 \times 10^{4}$ & $1,8(\mathrm{~g} / 100 \mathrm{ml})$ \\
\hline & 500 & $4,3 \times 10^{4}$ & $4,6 \times 10^{4}$ & $4,7 \times 10^{4}$ & $5,1 \times 10^{4}$ & $5,5 \times 10^{4}$ & $3,6(\mathrm{~g} / 250 \mathrm{ml})$ \\
\hline & 1000 & $2,7 \times 10^{4}$ & $3,9 \times 10^{4}$ & $4,7 \times 10^{4}$ & $4,8 \times 10^{4}$ & $5,2 \times 10^{4}$ & $7,0(\mathrm{~g} / 500 \mathrm{ml})$ \\
\hline & 2000 & $3,9 \times 10^{4}$ & $4,4 \times 10^{4}$ & $5,5 \times 10^{4}$ & $6,1 \times 10^{4}$ & $6,7 \times 10^{4}$ & $43,0(\mathrm{~g} / 1000 \mathrm{ml})$ \\
\hline & 4000 & $4,2 \times 10^{4}$ & $4,7 \times 10^{4}$ & $5,3 \times 10^{4}$ & $5,9 \times 10^{4}$ & $6,8 \times 10^{4}$ & $152,0(\mathrm{~g} / 2000 \mathrm{ml})$ \\
\hline \multirow{6}{*}{$\mathrm{TOH}$} & 100 & $3,3 \times 10^{4}$ & $3,6 \times 10^{4}$ & $4,1 \times 10^{4}$ & $4,4 \times 10^{4}$ & $4,5 \times 10^{4}$ & $0,7(\mathrm{~g} / 50 \mathrm{ml})$ \\
\hline & 200 & $3,6 \times 10^{4}$ & $4,1 \times 10^{4}$ & $4,4 \times 10^{4}$ & $4,6 \times 10^{4}$ & $5,1 \times 10^{4}$ & $1,4(\mathrm{~g} / 100 \mathrm{ml})$ \\
\hline & 500 & $2,7 \times 10^{4}$ & $3,6 \times 10^{4}$ & $4,5 \times 10^{4}$ & $5,3 \times 10^{4}$ & $6,1 \times 10^{4}$ & $4,7(\mathrm{~g} / 250 \mathrm{ml})$ \\
\hline & 1000 & $3,2 \times 10^{4}$ & $4,3 \times 10^{4}$ & $5,1 \times 10^{4}$ & $5,6 \times 10^{4}$ & $5,8 \times 10^{4}$ & $8,3(\mathrm{~g} / 500 \mathrm{ml})$ \\
\hline & 2000 & $3,4 \times 10^{4}$ & $3,7 \times 10^{4}$ & $5,3 \times 10^{4}$ & $5,8 \times 10^{4}$ & $6,6 \times 10^{4}$ & $62,2(\mathrm{~g} / 1000 \mathrm{ml})$ \\
\hline & 4000 & $3,5 \times 10^{4}$ & $3,9 \times 10^{4}$ & $5,4 \times 10^{4}$ & $5,9 \times 10^{4}$ & $6,7 \times 10^{4}$ & $129,6(\mathrm{~g} / 2000 \mathrm{ml})$ \\
\hline \multirow{6}{*}{ UIK } & 100 & $3,4 \times 10^{4}$ & $3,8 \times 10^{4}$ & $4,8 \times 10^{4}$ & $4,9 \times 10^{4}$ & $5,3 \times 10^{4}$ & $0,6(\mathrm{~g} / 50 \mathrm{ml})$ \\
\hline & 200 & $4,1 \times 10^{4}$ & $4,7 \times 10^{4}$ & $4,9 \times 10^{4}$ & $5,6 \times 10^{4}$ & $6,1 \times 10^{4}$ & $2,0(\mathrm{~g} / 100 \mathrm{ml})$ \\
\hline & 500 & $4,1 \times 10^{4}$ & $4,7 \times 10^{4}$ & $4,9 \times 10^{4}$ & $5,4 \times 10^{4}$ & $6,2 \times 10^{4}$ & $5,9(\mathrm{~g} / 250 \mathrm{ml})$ \\
\hline & 1000 & $2,5 \times 10^{4}$ & $3,2 \times 10^{4}$ & $4,7 \times 10^{4}$ & $4,7 \times 10^{4}$ & $5,2 \times 10^{4}$ & $11,7(\mathrm{~g} / 500 \mathrm{ml})$ \\
\hline & 2000 & $3,4 \times 10^{4}$ & $4,2 \times 10^{4}$ & $5,2 \times 10^{4}$ & $5,9 \times 10^{4}$ & $6,9 \times 10^{4}$ & $29,4(\mathrm{~g} / 1000 \mathrm{ml})$ \\
\hline & 4000 & $3,1 \times 10^{4}$ & $3,7 \times 10^{4}$ & $4,5 \times 10^{4}$ & $5,3 \times 10^{4}$ & $6,3 \times 10^{4}$ & $48,8(\mathrm{~g} / 2000 \mathrm{ml})$ \\
\hline
\end{tabular}

Laboratuvarda mikroskop çalışmamız sırasında 10x40'llk objektifte, $C$. vulgaris hücrelerinin büyüklükleri 6 ila $10 \mu$ arasında tespit edilmiştir. Bazı suşların diğerlerine göre daha küçükken bazılarının da daha büyük olduğu gözlenmiştir. GURH suşunda hücreler oldukça büyük ve yaklaşık $10 \mu$ (Şekil 3a), GUMSH suşunda hücreler tipik kloroplasta sahip $10 \mu$ (Şekil 3b), AUFFH suşunda hücreler 6 ila $10 \mu$ arasında (Şekil 3c), TOH suşundaki hücreler $6 \mu$ (Şekil 3d), UIK suşunda hücreler daha küçük, yoğun ve $5 \mu$ (Şekil 3e) büyüklüğünde ölçülmüşlerdir.

Alglerin yaşama ortamlarının incelenmesi sonucunda bu organizmalarm belirli besin maddelerine gereksinim duydukları kesin olarak ortaya çıkarılmıştır. Yapılan çalışmalara göre algler karbon, azot, fosfor, kükürt, magnezyum, sodyum, potasyum, demir, mangan, iz elementler ve organik faktörlere gereksinim duymaktadırlar (Schenk vd. 2008; Kumar ve Das 2012; Feng vd. 2012). Araştırmamızda Bold Wynne besiyeri hazırlanmış, bu besi ortamında $C$. vulgaris' in maksimum üreme hizının yapilan deneyler sonucunda $\mathrm{pH}$ 6,5-7 aralığında olduğu tespit edilmiş ve çalışmalar bu pH aralığında yapılmıştır.

Alg kültürleri bir ışık kaynağına ihtiyaç duyarlar. Çünkü $1 s ̧ 1 \mathrm{k}$ fotosentezin enerji kaynağıdır. Işık yoğunluğuna karşı fotosentez hızı doğrusal bir şekilde artar. Yüksek 1şı yoğunlukları fotosentezi inhibe eder, düşük yoğunlukları ise fotosentezi sinırlayıc1 özelliğe sahiptir. Işığın yoğunluğu ve süresi kültürlerin verimliliği açısından önemlidir. Başlangıçta 1şık yoğunluğuna paralel şekilde artan 
organik üretim, kültürün daha ileri safhalarında sınırlayıcı bir faktör olarak ortaya çıkmaktadır. $\mathrm{Bu}$ sınırlayıc1 etki ortamdaki hücre konsantrasyonunun bir sonucu olarak hücrelerin birbirlerini gölgelemesi ve 1şı̆̆a doygun hale gelen hücrelerin daha fazla 1şık enerjisi kullanmaması nedeniyle olur (Borcaklı 1987; Benli ve Uçal 1990). Az yoğun kültürlerde gelen 1şığın ancak \%2'si $7 \mathrm{~cm}$ derinliğe inerken, orta yoğun kültürlerde bu oran $\% 20$ yani $3 \mathrm{~cm}$ 'lik tabakalara ulaşabilir (Cirik ve Gökpınar 1993). Bu da kültürlerdeki verimi azaltmaktadır. Kültür uygulamaları suni aydınlatma kaynakları ile yürütülecekse, bunların güneş 1şığına eşdeğer kaynaklar olmasına dikkat edilmelidir. Bu işlem için genellikle floresan lambalar (daylight veya COOwhite) ve karanlık/aydınlık farklı periyotlar kullanılmaktadır (Amini vd. 2012). Yaptığımız çalışmalarda daylight floresan lambalar (150 $\left.\mu \mathrm{mol} . \mathrm{m}^{-2} . \mathrm{s}^{-1}\right)$ ile $16: 8$ aydınlık/karanlık periyodu uygulandığında maksimum üreme tespit edilmiştir.

Alg kültürlerinin biyolojik aktiviteleriyle ortam sıcaklıkları arasında genel bir ilişki bulunmaktadır. Büyüme hızları belirli bir optimuma kadar sıcaklığa bağlı olarak artar. Ancak, bu noktadan sonra azalmaya başlar (Behrens 2005). Bu optimum pek çok deniz ve tatlısu türleri için $18-25{ }^{\circ} \mathrm{C}$ aralığındadır. Sabit sıcaklıktaki kültür koleksiyonu odaları genellikle $18{ }^{\circ} \mathrm{C}$ 'de tutulur (Cirik ve Gökpınar 1993). Bu nedenle alg kültür salonlarındaki sıcaklığın kontrol edilmesi, düzensiz sıcaklık değişimlerini önlemek için önem taşımaktadır. Kültürlerimizin yetiştirildiği laboratuvar ortamında sıcaklık 22-25 ${ }^{\circ} \mathrm{C}$ olarak ölçülmüş ve bu sıcaklık değerinin sabit kaldığ 1 tespit edilmiştir.

Güneş enerjisi sayesinde sulardaki yeşil bitkilerin oluşturduğu canlı madde biyomas olup, belli bir zamanda belirli bir alan veya hacimde üretilen canlı madde miktarı olarak ifade edilir. Kültürlerin kantitatif değerlendirilmesi hücre sayısı, optik yoğunluk, kuru veya yaş ağırlık, klorofil miktarı, organik karbon vb. gibi algal büyümeyle ilgili parametrelerin hassas bir şekilde ölçülmesiyle elde edilir (Cirik ve Gökpınar 1993; Andersen 2005).

Algal büyümedeki karakteristik fazlar kesikli kültür tekniği ile yapılan kültürlerde görülebilir. Kültür ortamına aş1lanan hücrelerin büyümeye başlamadan önce ortama uyum için bir duraklama devresi geçirmesi, sonra logaritmik bir şekilde artmas1, belli bir noktada büyümenin yavaşlayarak sabit bir evreye girmesi kesikli kültürlerde gözlenir (Chia vd. 2013; Hakalin vd. 2014). Belirli bir müddet sonra üremeye başlayan hücreler ortamdaki nutrientlerin tükenmesi ve büyümenin ulaştığı maksimum noktada ışığa doygun hücrelerin oluşması gibi faktörlerin etkisi ile hücrelerin ulaştıkları bir maksimumdan sonra büyüme durmaktadır (Becker 1994). Önceki çalışmalarımızda 6 farklı besi yerinde $10 \mathrm{ml}$ 'lik tüplerin içerisinde $C$. vulgaris şuslarının yetiştirilmesi yapılmıştır. $\mathrm{Bu}$ çalışma sonrasında en iyi üreme gösteren 5 suş ve hücre sayısı bakımından en iyi üredikleri besi ortamı olarak tespit edilen Bold Wynne yığın kültür üretilmesi için seçilmiştir. 4000 ml'lik yığın kültürlerin 120. saatte yapılan hücre sayımlarında en yüksek değer AUFFH suşunda $6,8 \times 10^{4} \mathrm{~h} / \mathrm{ml}$ olarak tespit edilmiş, bu suşu sirasiyla TOH $6,7 \times 10^{4} \mathrm{~h} / \mathrm{ml}$, UIK $6,3 \times 10^{4} \mathrm{~h} / \mathrm{ml}$,

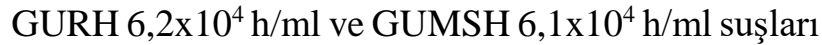
izlemiştir. Yaş ağırlıkları açısından 4000 ml'lik yığın kültürler için yine AUFFH $152(\mathrm{~g} / 2000 \mathrm{ml})$ ile en yüksek miktar elde edilirken onu sirasıyla TOH 129,6 (g/2000 ml), GURH 120,8 (g/2000 ml), GUMSH $84,3(\mathrm{~g} / 2000 \mathrm{ml})$, UIK 48,8 (g/2000 ml) takip etmiştir. AUFFH, TOH, GUMSH ve GURH suşlarının hücre sayıları ve biyomas miktarları birbirlerine orantılı çıkmakla birlikte UIK suşunun hücre sayısı yüksek çıkarken biyomasının diğerlerine nazaran daha düşük çıktığ gözlenmiştir. Bunun nedeninin UIK suşundaki hücrelerin üreme sonrası gelişen yeni genç hücreler olabileceği düşünülmektedir. Vaiciulyte vd. (2014) kültürlerin yağ içeriklerinin artırılması için farklı besi ortamları ile yaptıkları yı̆̆ın kültür üretimi çalışmalarında hücre sayılarını 230-250 (hücre x106/L), kuru ağırlıklarını 2,04-2,2 g/L olarak tespit etmişlerdir. Chia vd. (2013) yılında yaptığı çalışmada, hücre sayısının biyomas için önemli bir parametre olduğunu belirterek besi ortamına göre değiştiğini ifade etmiştir. C. vulgaris ile yaptıkları bu çalışmada LC Oligo ortamından yüksek algal üreme ve hücre yoğunluğunu elde ettiklerini $\left(2.74 \times 10^{6}\right.$ hücre $\left.\mathrm{mL}^{-1}\right)$ belirtmiştir. $\mathrm{Bu}$ sonuçlar bizim değerlerimiz ile paralellik göstermektedir.

Sonuç olarak mikroalglerden elde edilen pigmentler (Hosikian vd. 2010), besin maddeleri ile tıbbi takviyeler (Rasmussen vd. 2007), ağır metallerin sulardan temizlenmesi (Chu vd. 2009; Ruiz-Marin vd. 2010), karbondioksit emisyonunun düşürülmesi ve biyodizel (Al-Iwayzy vd. 2014; Brennan ve Owende 2009) üretimi bu mikroorganizmaların ne kadar önemli olduklarını göstermektedir. Bu çalışmanın sonucunda kesikli kültür sisteminde mikroalg yetiştiriciliği için gerekli koşulların araştırılarak sağlandığ miktarının mikroalg büyümesindeki etkisi, farklı 1şı/karanlık döngüleri, sıcaklık, $\mathrm{pH}$ ve besleyici ortam formülasyonları gibi diğer parametrelerin etkileri ile Bold Wynne besi ortamının hücre sayısı ve biyomas ağırlığını artırdığ gözlenmiştir. Böylece mikroalg türlerinin izole edilerek yetiştirilmesi için tecrübe kazanılmış ve farklı türlerin izolasyonu ve yetiştirilmesi çalışmalarına başlanmıştır. 


\section{Kaynaklar}

Aguoru CU, Okibe PO. 2015. Content and composition of lipid produced by Chlorella vulgaris for biodiesel production. Advances in Life Science and Tech. 36 (2015):96-100.

Al-lwayzy SH, Yusaf T, Al-Juboori RA. 2014. Biofuels from the Fresh Water Microalgae Chlorella vulgaris (FWM-CV) for Diesel Engines. Energies 7(3):1829-1851. doi:10.3390/en7031829

Amini KZ, Seyfabadi J, Ramezonpour Z. 2012. Effect of light intensity and photoperiod on bimass and fatty acid composition of the microalgae, Chlorella vulgaris. Aquacult. Int. 20(1):41-49. doi: 10.1007/s10499-011-9440-1

Andersen RA. 2005. Algal culturing techniques. Burlington: Elsevier Academic Press 578 p.

Baydar S. 1990. Tohumsuz bitkiler sistematiği. Trabzon: Karadeniz Teknik Üniversitesi $261 \mathrm{~s}$.

Becker EW. 1994. Microalgae: biotechnology and microbiology. New York: Cambridge University Press 293 p.

Behrens PW. 2005. Photobioreactors and fermentors: the light and dark sides of growing algae. In: Andersen RA, editors. Algal culturing techniques, London: Elsevier Academic Press. p. 189-204.

Benli HA, Uçal O. 1990. Deniz canlı kaynakları yetiştirme teknikleri. Bodrum: T.C. Tarım, Orman ve Köy İşleri Bakanlığı, Su Ürünleri Araştırma Ens. Müd. Seri A. Yayın no:3 $105 \mathrm{~s}$.

Borcaklı M. 1987. Yeni gıda kaynağı olarak mikroalgler ve üretim yöntemleri. Kocaeli: TÜBİTAK MAM Beslenme ve Gıda Teknolojileri ile Soğutma Tekniği Araştırma Bölümü. Cilt 2. Yayın no:12. 73-86.

Borowitzka MA, Borowitzka JL. 1988. Micro-algal biotechnology. Cambridge: Cambridge University Press.

Brennan L, Owende P. 2009. Biofuels from microalgae A review of technologies for production, processing and extractions of biofuels and co-products. Renewable and Sustainable Energy Reviews 14(2):557-577. doi:10.1016/j.rser.2009.10.009

Chia MA, Lombardi AT, Melao MDG. 2013. Growth and biochemical composition of Chlorella vulgaris in different growth media. An Acad Bras Cienc. 85(4):1427-1438. doi: 10.1590/0001-3765201393312

Chu WL, See TC, Phang SM. 2009. Use of immobilised Chlorella vulgaris for the removal of colour from textile dyes. J Appl Phycol. 21(6): 641-648. doi: 10.1007/s10811-008-9396-3

Cirik S, Gökpınar Ş. 1993. Plankton Bilgisi ve Kültürü. İzmir: Ege Üniversitesi Basımevi 274 s.

Cohen Z. 1999. Chemical from Microalgae. London: Taylor\&Francis UK 419 p.

CSIRO 2016. Commonwealth Scientific and Industrial Research Organisation. Microalgal Isolation Techniques; [Erişim Tarihi: 29.11.2016]. Erişim Adresi:http://www.marine.csiro.au/microalgae/ methods/microalgal\%20isolation\%20techniques.htm
Feng P, Deng L, Hu F. 2012. Lipid accumulation and growth characteristics of Chlorella zofingiensis under different nitrate and phosphate concentrations. J Biosci Bioeng. 114(4):405-410. doi: 10.1016/j.jbiosc.2012.05.007

Guillard RRL, Sierachiki MS. 2005. Counting cells in cultures with the light microscope. In: Andersen RA, editors. Algal culturing techniques, London: Elsevier Academic Press. p. 239-252.

Hakalin NLS, Paz AP, Aranda DAG, Moraes LMP. 2014. Enhancement of cell growth and lipid content of a freshwater microalga Scenedesmus sp. by optimizing nitrogen, phosphorus and vitamin concentrations for biodiesel production, Natural Science. 6(12):1044-1054. doi: 10.4236/ns.2014.612095

Hamedi S, Mahdavi MA, Gheshlaghi R. 2016. Improved lipid and biomass productivities in Chlorella vulgaris by differing inoculation medium from production medium. Biofuel Research Journal 10(2016):410-416. doi: 10.18331/BRJ2016.3.2.6

Hosikian A, Lim S, Halim R, Danquah KM. 2010. Chlorophyll extraction form microalgae: A review on the process engineering aspects. International Journal of Chemical Engin. 2010:1-11. doi: $10.1155 / 2010 / 391632$

Iwamoto H. 2004. Industrial production of microalgal cellmass and secondary products-major industrial species Chlorella. In: Richmond A, editors. Handbook of microalgal culture: biotechnology and applied phycology. UK: Blackwell Science 255-263.

Kumar K, Das D. 2012. Growth characteristics of Chlorella sorokiniana in airlift and bubble column photo-bioreactors. Bioresour Technol. 116:307-313. doi: 10.1016/j.biortech.2012.03.074

Murdock JN, Wetzel DL. 2009. FT-IR Microspectroscopy enhances biological and ecological analysis of algae. Appl. Spectros. 44(4):335-361. doi: 10.1080/05704920902907440

Parvin M, Zannat MN, Habib MAB. 2007. Two important technique for isolation of microalgae. Asian Fisheries Science. 20(1):117-124.

Prescott GW. 1968. The algae. Boston: Michigan State University p. 37-67.

Prescott GW. 1973. Algae of the Western Great Lakes Area. Michigan: Michigan State University Department of Botany and Plant Pathology 1004 p.

Rasmussen RS, Morrissey T, Steve LT. 2007. Marine biotechnology for production of food ingredients. Advances in Food and Nutrition Res. 52 (2007):237-292. doi: 10.1016/S1043-4526(06)52005-4

Richmond A. 2004. Handbook of microalgal culture: biotechnology and applied phycology. 2nd ed. Australia: Blackwell Science Ltd. 719 p.

Ruiz-Marin A, Mendoza-Espinosa L, Stephenson T. 2010. Growth and nutrient removal in free and immobilized green algae in batch and semi-continuous cultures treating real wastewater. Bioresource Techno. 101(1): 58-64. doi: 10.1016/j.biortech.2009.02.076 
Santhosh S, Dhandapani R, Hemalatha NA. 2016. A Review on potential biotechnological applications of microalgae. J App Pharm Sci. 6(08): 179-184. doi: 10.7324/JAPS.2016.60829

Schenk PM, Thomas-Hall SR, Stephens E, Marx UC, Mussgnug JH, Posten C, Kruse O, Hankamer B. 2008. Second generation biofuels: high-efficiency microalgae for biodisel production. BioEnergy Res. 1(1):20-43. doi: $10.1007 / \mathrm{s} 12155-008-9008-8$
Shihira I. 1965. Chlorella physiology and taxonomy of forty-one isolates. Maryland: University of Maryland, College Park 97 p.

Vaiciulyte S, Padovani, G, Kostkeviciene J, Carlozzi P. 2014. Batch growth of Chlorella vulgaris CCALA 896 versus semi-continuous regimen for enhancing oil-rich biomass productivitiy. Energies 7(6):3840-3857.

doi:10.3390/en7063840 